Mappemonde

Revue trimestrielle sur l'image géographique et les formes du territoire

$124 \mid 2018$

Varia

Bruno FULIGNI, Royaumes d'aventure. Ils ont fondé leur propre État

Paris : Les Arènes, 2016, 320 p.

Christine Zanin

OpenEdition

Journals

Édition électronique

URL : http://journals.openedition.org/mappemonde/363

DOI : 10.4000/mappemonde.363

ISSN : 1769-7298

Éditeur

UMR ESPACE

Référence électronique

Christine Zanin, «Bruno fuLıGNI, Royaumes d'aventure. Ils ont fondé leur propre État », Mappemonde [En ligne], 124 | 2018, mis en ligne le 10 juillet 2018, consulté le 25 septembre 2020. URL : http:// journals.openedition.org/mappemonde/363; DOI : https://doi.org/10.4000/mappemonde.363

Ce document a été généré automatiquement le 25 septembre 2020.

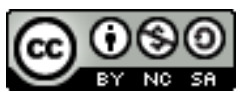

La revue Mappemonde est mise à disposition selon les termes de la Licence Creative Commons Attribution - Pas d'Utilisation Commerciale - Partage dans les Mêmes Conditions 4.0 International. 


\section{Bruno FULIGNI, Royaumes d'aventure. Ils ont fondé leur propre État}

Paris : Les Arènes, 2016, 320 p.

Christine Zanin

\section{RÉFÉRENCE}

Bruno fULIGNI. Royaumes d'aventure. Ils ont fondé leur propre État. Paris : Les Arènes, 2016, $320 \mathrm{p}$. 
1 Entre livre d'aventure, atlas iconoclaste et encyclopédie illustrée, le livre de Bruno Fuligni, Royaumes d'aventure, publié en 2016 par la très belle maison d'édition des Arènes, suscite l'étonnement. Nous pensions tout connaitre du Monde, tout avoir exploré, tout avoir cartographié... et pourtant l'auteur nous donne à rêver à travers l'histoire et la présentation géographique de quelques états autoproclamés! Qui connaît le royaume des Ecréhouy où régnait sur trois hectares un monarque solitaire au large de l'ile anglo-normande de Jersey? Qui s'est déjà promené dans l'enclave de l'Arbézie libre, principauté oubliée de dix ares située entre le Jura français et la Suisse dans une zone montagneuse et forestière à 1150 mètres d'altitude? Ou encore, qui a

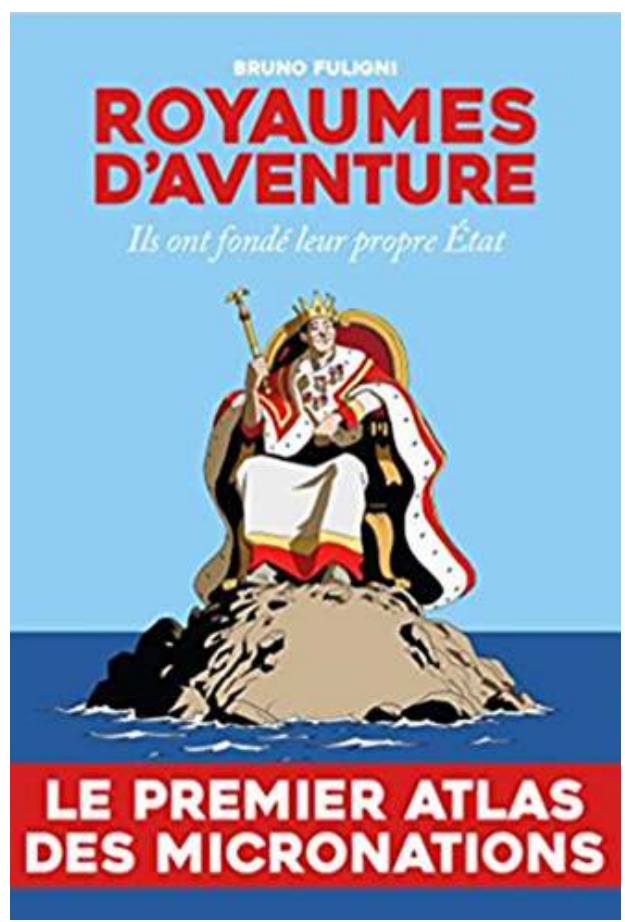
visité le territoire républicain roulant de Kugelmugel qui n'est qu'une simple maison en forme de boule de huit mètres de diamètre construite par l'artiste Edwin Lipburge?

Ce qui est intéressant ici, ce n'est pas tant la géographie de tel ou tel petit état coincé entre deux empires, ou l'histoire de telle ou telle folie d'hommes aventureux, mais bien le nombre de ces micronations. Bruno Fuligni présente dans ce parcours initiatique, pour quiconque aurait la vocation de devenir monarque, pas moins de 34 «destins d'hommes qui voulurent être roi ». Ils sont tous plus fascinants les uns que les autres. Dans un style relevé et un rythme court, nous apprenons beaucoup sur ces royaumes pirates ou ces pays virtuels n'existant que sur Internet. Le voyage est découpé en trois types de royaumes: ceux des îles lointaines, les empires éphémères et les enclaves oubliées. Chaque royaume est présenté comme un terrain d'aventures d'hommes très différents, marins, flibustiers, aventuriers, pionniers, intellectuels, mais avec une même ambition marquée et une soif de liberté. Ce qui est aussi étonnant dans ce voyage est la volonté de ces monarques d'élever ces nouveaux états au rang d'une nation classique avec tous ses attributs de pouvoir que sont le drapeau et la monnaie. Un dernier chapitre marque cet ouvrage captivant, une conclusion qui n'est rien d'autre qu'un mode d'emploi pour accéder à la souveraineté territoriale, «le droit des héros à fonder des États» (Hegel) : 1 - trouver un territoire disponible ; 2 - revendiquer son territoire auprès des instances internationales ; $3-$ ne pas oublier de se tourner vers l'espace ; 4 - voyager dans le temps et réactiver un État «injustement " annexé ; 5 adopter un statut de gouvernement en exil; 6- être reconnu sur la scène internationale. Ces six points pouvant donner lieu à une multitude de stratagèmes plus ou moins honnêtes pour accéder au trône, comme en attestent les nombreux exemples présentés. Pour finir, toutes ces micronations sont légitimées par une iconographie abondante et variée constituée de photos, cartes et portraits des rois et empereurs de ces royaumes. 


\section{AUTEURS}

\section{CHRISTINE ZANIN}

Université Paris Diderot, UMS RIATE 